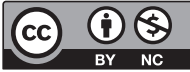

\title{
Modalidades psíquicas irredutíveis: Levinas e a negação originária
}

\section{Irreducible psychical modalities: the primal negation in Levinas' thought}

\section{Marcelo Fabri}

Doutor em Filosofia pela Universidade Estadual de Campinas (Unicamp), professor do Departamento de Filosofia da Universidade Federal de Santa Maria (UFSM), Santa Maria, RS - Brasil, e-mail: fabri@smail.ufsm.br

\section{Resumo}

$\mathrm{O}$ artigo examina a ambiguidade do conceito fenomenológico de modalidade segundo Levinas. Primeiramente, considera-se a tese atribuída a Heidegger segundo a qual o sujeito humano é uma modalidade da manifestação do ser. O conceito husserliano de consciência intencional também será interpretado segundo esta tese. Em seguida, examinam-se as modalidades psíquicas irredutíveis descobertas e descritas pela própria fenomenologia husserliana. O psiquismo irredutível, cujo acesso é dado pelo método fenomenológico, não é modalidade do ser, mas do outramente que ser. Entretanto, a chave para compreender este psiquismo é o fenômeno originário da negação. Na nossa perspectiva, a tese de Levinas não se encontra 
tão distante da tese de Husserl, embora a diferença entre os dois filósofos deva ser preservada.

Palavras-chave: Modalidade. Fenomenologia. Ser. Negação. Levinas.

\begin{abstract}
The paper aims to examine the ambiguity of the phenomenological concept of modality in Levinas' thought. First of all, we consider the heideggerian's thesis in which human subjectivity is a modality of the manifestation of being. Husserl's concept of intentional consciousness will be interpreted according to this thesis. Secondly, we examine the irreducible psychical modalities discovered and described in exemplar way by Husserl's phenomenology itself. This irreducible consciousness, which access is given by the phenomenological method itself, is not the modality of being, but of otherwise than being. However, the key to understand this consciousness is the primal phenomenon of negation. In our perspective, Levinas' thesis is not so far from Husserl's thesis, although the distance between them must be preserved.
\end{abstract}

Keywords: Modality. Phenomenology. Being. Negation. Levinas.

\title{
Introdução
}

O conceito fenomenológico de modalidade é fundamental para a compreensão do pensamento de Levinas. Nosso propósito, aqui, é apresentar a ambiguidade deste conceito na escrita levinasiana. Para tanto, vamos considerar duas proposições fundamentais, que sempre ressurgem em tal escrita: a primeira, muito mais frequente, é esta: a fenomenologia é um deixar aparecer os fenômenos, tais como eles são, sendo que este aparecer é o evento essencial do próprio ser (LEVINAS, 1994, p. 117). De acordo com esta tese, a manifestação do ser requer a consciência e o $e u$, melhor dizendo, o sujeito é uma modalidade da manifestação do ser (LEVINAS, 1996, p. 34). Quanto à segunda proposição, que é menos frequente, nós a transcrevemos a partir da herança husserliana ressoando reiteradamente na escrita de Levinas. Ela se diz assim: A subjetividade, em sentido husserliano, é, sob certos aspectos, uma 
resistência ou destacamento do sujeito em relação ao sistema, à totalidade e ao ser (LEVINAS, 1994, p. 121). Comentando a via aberta por Husserl, Levinas afirma que a subjetividade do sujeito se compreende a partir de modalidades psíquicas irredutíveis ao saber e ao ser. A análise fenomenológica dessas modalidades permite uma descrição da situação temporal que está aquém e além do ser. Eis por que o psiquismo irredutível, cujo acesso é dado pelo próprio método fenomenológico, não é modalidade do ser, mas do outramente que ser. Na nossa perspectiva, trata-se do conceito levinasiano de modalidade: ambiguidade do ser e do outro do ser. Assim, perguntamos: como entender a modalidade do outramente?

Levinas, numa espécie de proximidade/distância em relação a Husserl, realiza uma descrição fenomenológica da origem da negação. Por um lado, ele admite, interpretando Heidegger, que todas as formas modais desembocam na temporalidade da essência (isto é, no verbo ser). Até mesmo nossa relação ao Nada se compreende, em Heidegger, a partir da relação ao ser. Em Levinas, ao contrário, a negação originária é irredutível ao ser. Como entender este surgimento da negação? Para além do não apofântico e da relação ao Nada, bem como da passagem dialética pelo outro (Hegel), trata-se de descrever a irrupção de uma vivência irredutível: o sofrimento ou a dor humana. Ao descrever esta vivência, Levinas procura explicitar filosoficamente a ambiguidade do ser e do outro que o ser. Uma análise do sofrimento deve mostrar esta ambiguidade. Na origem do não apofântico encontra-se a absurdidade da dor, dissolução de todo o sentido, fim de toda justificação racional presente na teodiceia. Curiosamente, é na fronteira desta mesma absurdidade que se torna possível o outramente que ser: significação como um-para-o-outro, subjetividade como responsabilidade (outro no mesmo), temporalização como transcendência.

\section{Abertura e clausura propiciadas pelo verbo ser}

Ao sublinhar a dimensão verbal do ser, o pensamento de Heidegger surge, para Levinas, como modelo privilegiado para se interpretar toda uma orientação do pensamento, sobretudo na Filosofia contemporânea. Em que sentido? Ora, se o eu possui uma consistência, esta se deve a um conjunto de relações, muito mais do que a uma substancialidade ou consciência fechada em si mesma. Guiado pela sua interpretação de Heidegger, Levinas argumenta que, nos filósofos contemporâneos, o real deixa de ser pensado a 
partir do modelo do objeto para descobrir-se como relação, duração, história, pessoa, finitude, etc. Por que dizer que é a interpretação de Heidegger que se faz notar aqui? Na perspectiva levinasiana, aquilo que importa ao pensamento contemporâneo é o valor que se confere ao sentido que anima a vida concreta: percepção sensível, comportamento econômico, intuição criadora, sentimento, são tantos termos que indicam esta animação (LEVINAS, 1995, p. 103). O pensamento contemporâneo é interpretado, assim, sob os influxos de Ser e tempo, pois o contato com o verbo ser marca a origem de toda significação. Nas palavras de Levinas (1995, p. 104, grifos do autor): “o termo modalidade não designa mais unicamente o possível, o real e o necessário da lógica formal, mas uma diversidade de estruturas ontológicas".

A ontologia, neste caso, não é uma teoria sobre o ser. Ela não se reduz a nenhuma tematização. O que importa é reconhecer que há um contexto a partir do qual toda predicação e toda tematização serão possíveis. Transcendendo o objeto em direção ao ser, o pensamento contemporâneo, lido a partir de categorias heideggerianas, abriu novas possibilidades de reflexão sobre as relações inter-humanas. A obra de Martin Buber, por exemplo, que inaugura uma filosofia do diálogo fundada sobre o termo "tu", é um exemplo disso. Já para Bérgson, a verdade não é o simples reflexo do ser, mas decisão, invenção, criação (LEVINAS, 1995, p. 27). Ora, em todas essas possibilidades ou aberturas, permanece uma orientação básica: a verdade é um acontecimento fundamental do ser.

Mas, apesar de toda abertura trazida pela dimensão verbal do ser, Levinas insiste que a inteligibilidade continua sendo devedora da relação a uma neutralidade, isto é, o sujeito não deixa de ser concebido como uma modalidade do próprio ser ou da essência. Vejamos como Levinas interpreta esta "submissão":

A subjetividade, a consciência, o Eu - supõem o Dasein, que pertence à essência como modalidade segundo a qual esta essência se manifesta, sendo que a manifestação da essência é o essencial da essência; a experiência e o sujeito que faz a experiência constituem a maneira mesma na qual, em uma dada "época" da essência, a essência se realiza, isto é, se manifesta (LEVINAS, 1996, p. 34-35).

Ora, a tese segundo a qual o sujeito é modalidade da essência foi, também, uma marca decisiva do pensamento de Hegel. Certo, a ontologia fundamental de Ser e tempo não pode ser interpretada como sendo a expressão contemporânea da dialética hegeliana. No entanto, Heidegger partilha com 
Hegel de um mesmo princípio: uma subjetividade irredutível à essência é impensável (LEVINAS, 1996, p. 34). Na perspectiva hegeliana, a essência não é senão o ser aparecendo a si mesmo (HEGEL, 1987, p. 89). A essência é o ser retornando a si, depois de passar pela diferença, ou ainda, é uma espécie de autorreflexividade ou autorreferencialidade. O ser desenvolvido pressupõe a negatividade, a mediação, o devir como condição para se tornar aquilo que se é. Nesse sentido, "a reflexão sobre si, que é também reflexão sobre outra coisa e vice-versa, é a essência posta como totalidade" (HEGEL, 1987, p. 93).

Segundo Levinas, a essência enquanto totalidade pode ser comparada a um "destino" mítico, no qual os fios tecidos pelas Moiras devem manter unificados, no interior do "todo", as diferenças e as modalidades que compõem este todo (LEVINAS, 1996, p. 20). Tomadas em si mesmas, as diferenças e as modalidades que compõem a ordem tecida constituem uma negação impossível, uma exceção impronunciável, um "outro" que a ordem não reconhece ou não admite. Curiosamente, as modalidades tomadas fora da ordem (do destino ou da essência) não deixam de ser uma forma de nadificação. Assim,

a essência aspira a recobrir (recouvrir) e a reapoderar-se (recouvrer) de toda ex-ceção - a negatividade, a nadificação, o não-ser, que, desde Platão, "em certo sentido, é". Por conseguinte, deve-se mostrar que a ex-ceção do "outro que o ser" - para além do não-ser - significa a subjetividade humana, o simesmo que rejeita as reapropriações da essência (LEVINAS, 1996, p. 21).

De nossa parte, afirmamos e enfatizamos que Levinas descreve a negação apofântica como já fundada numa negação originária, entendida como resistência ao destino da essência. Como se sabe, a modalidade rebelde ou anárquica é, para ele, uma negatividade que $m e$ ordena ao rosto de outrem (LEVINAS, 1996, p. 26). A negatividade é, portanto, o reverso ou questionamento de um destino, uma recusa, ainda que recorrente, ${ }^{1}$ da submissão ao movimento de expansão do ser. A negatividade é modalidade da interrupção, interrupção esta que pressupõe o $\mathrm{Si}(\mathrm{So} i)$ como passividade ou ser encarnado, exposto ao sofrimento, à doença e à morte (LEVINAS, 1996, p. 172). O que é interrompido? A identidade irreversível da essência. O outramente que ser de que fala Levinas é interrupção de uma ordem irreversível. Mas neste momento

1 “[...] Esta recorrência que se pode chamar, com razão, de negatividade (negatividade anterior ao discurso e que é a pátria irrecusável da negatividade dialética), esta recorrência da contração - é Si (Soi)" (LEVINAS, 1996, p. 171). 
é preciso indagar: por que a negação originária não remonta à questão do Nada? Não teria o próprio Heidegger aberto uma possibilidade de questionar a inseparabilidade entre a subjetividade e o cognoscível, na medida em que, para este filósofo, a negação depende do nadificar do Nada, e não de uma atividade do entendimento? (HEIDEGGER, 1968, p. 53). A questão do Nada já não é um pensar a partir do choque da diferença, isto é, do outramente?

\section{De Heidegger a Husserl: a origem da negação}

Quando Heidegger põe a questão do Nada, ele o faz a partir do destino da metafísica. Enquanto pensa o ente, a metafísica esquece o Ser e, com isso, esquece também o Nada. É preciso pensar o Ser a partir do Nada, afirma Heidegger. Mas, diferentemente do que pensa a boa lógica, o Nada é outro em relação à coisa negada, à negatividade, à negação (HEIDEGGER, 1968, p. 53). O Nada é originariamente anterior a tudo isso. Toda operação do entendimento já depende de nossa relação ao Nada. Por isso, em vez de se dizer que o entendimento determina o Nada, melhor seria afirmar que, na medida mesma em que existimos, já sempre encontramos e "conhecemos" o Nada. Em outros termos, o Nada pode ser dado ou encontrado porque já o conhecemos previamente (HEIDEGGER, 1968, p. 54).

Na perspectiva heideggeriana, a angústia é a disposição afetiva privilegiada, única que poderia nos revelar o Nada. Na angústia, flutuamos em suspenso. Ela simplesmente oprime, tira-nos a palavra, golpeia-nos. Mas é importante observar que, para Heidegger, não se trata de um estado de ânimo ligado a alguém em particular. É o existente humano mesmo que, enquanto lançado no mundo, enquanto capaz de angustiar-se, experimenta o choque da presença do Nada. Ou ainda: é o próprio Dasein que, na angústia, se encontra numa espécie de copresença em relação ao Nada (HEIDEGGER, 1968, p. 60).

Para nosso propósito, importa destacar o seguinte. A experiência descrita agora pressupõe um movimento de recuo, uma experiência de repulsa ou estarrecimento diante de algo que fascina. Ora, quando Heidegger diz que o Nada, ele mesmo, nadifica (Das Nichts selbst nichtet), ele quer dizer que há, aí, a produção de uma alteridade, de um estranhamento. Tudo se passa como se o ser-aí fosse radicalmente outro em relação ao Nada. Por causa desta diferença, o existente humano pode descobrir-se diante da realidade existente ou mundo dos entes. É assim que se pode falar em transcendência, de um "ir além" daquilo que existe. O Nada, afirma Heidegger, põe a realidade humana 
diante da existência enquanto tal (HEIDEGGER, 1968, p. 62). O ser pessoal e a liberdade tornam-se, então, possíveis. A realização do ser-aí implica, de resto, este encontrar-se retido no interior do Nada.

Por conseguinte, é o nadificar do Nada que marca a origem da negação (HEIDEGGER, 1968, p. 63). Dito de outro modo, a negação só é modalidade na medida em que é um dos modos do comportamento que nadifica, ou enquanto modo que se funda no próprio nadificar do Nada. Com isso, nenhuma exclusividade ou prioridade será dada á negação enquanto tal. Modalidades negativas, tais como a recusa, a privação, a defesa são apenas possibilidades do comportamento negador. Essas modalidades são forças com as quais o ser-aí suporta sua condição, sem, no entanto, dominá-la. Assim, pode-se afirmar que, em Heidegger, as modalidades da negação, mencionadas acima, não são espécies de negação pura e simples (HEIDEGGER, 1968, p. 65). Além disso, se o Nada é a origem da negação, Hegel tem razão ao afirmar que o Ser e o Nada se compõem mutuamente (HEIDEGGER, 1968, p. 69). O pensamento é, portanto, um evento do Ser (HEIDEGGER, 1968, p. 79). Não importa o que aconteça ao homem, deve-se salvaguardar a verdade do ser (HEIDEGGER, 1968, p. 81).

Diante disso, Levinas pergunta: não seria possível descrever um modo (façon) de pensar capaz de questionar a tese de que o pensamento é um evento do Ser? Pode-se pensar o Ser a partir do Outro que o ser? Do ponto de vista metodológico, pensamos que a leitura levinasiana de Husserl é peça-chave na resposta a estas questões. Mas como sustentar esta tese se, em Levinas, o conceito husserliano de intencionalidade é reiteradamente interpretado como estando, de saída, implicado do dinamismo verbal do verbo ser, isto é, como um conceito que adquire sua força a partir da ontologia fundamental?²

Na nossa perspectiva, é forçoso reconhecer que, em seu esforço para refutar a tese de que a origem de toda significação encontra-se na compreensão de ser, Levinas lança mão de uma estratégia pouco notada entre seus estudiosos. Na proximidade de Husserl, Levinas afirma que o psiquismo da intencionalidade não se esgota na relação do pensamento com o pensado, melhor dizendo, ele explica que o pensamento não absorve aquele que pensa (LEVINAS, 1994, p. 120). Trata-se de mostrar que é possível, a partir de Husserl, descobrir uma negação anterior ao próprio Nada, sem apelo ao entendimento, e sem se voltar

2 Pelo menos, é isso que depreende da afirmação: “A correlação rigorosa entre aquilo que se manifesta e os modos da consciência permite a Husserl afirmar o seguinte. A consciência é prestadora de sentido, mas o ser comanda as modalidades da consciência que acedem a ele; o ser comanda o fenômeno" (LEVINAS, 2002, p. 211). 
para uma espécie de subjetividade soberana. A pergunta decisiva é, então, a seguinte. Como toma sentido um Nada que não é apenas negação da negação (Hegel), que não se identifica com a alteridade do Ser em relação ao ente, ou seja, que não emerge da copresença entre Dasein e Nada? Não seria possível retomar as possibilidades abertas pela fenomenologia, realizando uma epoché dos desenvolvimentos e prolongamentos que ela recebera graças à obra de Heidegger? Dizemos isso porque, na perspectiva levinasiana, a fenomenologia

afirma a solidariedade rigorosa entre todo inteligível e as modalidades psíquicas nas quais e pelas o inteligível é pensado [...]. A fenomenologia educou-nos a explicitar ou a elucidar um psiquismo a partir de um psiquismo irredutivel no qual ele é dado, a buscar, assim, o sentido na sua origem, a buscar o sentido originário. Este método, vindo de uma filosofia da aritmética e das investigações lógicas, afirma a primazia - o principado - do não-formal! (LEVINAS, 2002, p. 170).

É assim que a negação pode ser descrita em termos de modalidade psíquica irredutível. Em Idéias I, Husserl mostrara que a origem da negação se compreendia em relação à consciência posicional. Os momentos noemáticos constituídos (objeto intencional enquanto tal) têm na consciência de crença o seu ponto de partida. Ora, toda modificação ou modalização de caracteres noéticos trazem novos objetos de ser para a consciência (HUSSERL, 2006, § 105, p. 238). A negação é entendida como sendo uma modificação de uma posição tomada, ou seja, ela não é simples recusa de uma afirmação. Dito de outro modo, a consciência põe a passagem do ser ao não-ser em suas várias fases de modalização (HUSSERL, 2006, § 106, p. 239). Mas, perguntamos, por que um percurso temporal, que sempre se encontra referido a uma unidade estável, pode alterar-se modalmente? Na obra Experiência e juízo há uma resposta a esta questão. O "novo" sempre pode emergir inesperadamente, na consciência, sob a forma de uma "alteridade" que entra sem pedir licença, que frustra a expectativa de um movimento perceptivo. Husserl chamou esta alteração de "fenômeno originário da negação, da nadidade (der Nichtigkeit), ou da 'supressão' (der Aufhebung), do 'outramente' (des anders)" (HUSSERL, 1970, p. 105, grifo do autor). A negação ocorre antes mesmo de qualquer predicação, numa espécie de experiência receptiva ou passiva, em que um sentido novo se sobrepõe a um sentido que já estava constituído. Por exemplo: um interesse perceptivo originário pode descobrir-se negado, marcado por um impedimento (Hemmung) ou obstáculo. As modalizações são, assim, “impedimentos no 
decurso de um interesse perceptivo originário". A negação, por sua vez, é a interrupção (Abbruch) de um processo perceptivo (HUSSERL, 1970, p. 111).

Ora, é justamente de interrupção ou impedimento que fala Levinas ao se referir à modalidade do outramente. É certo que sua preocupação não recai sobre as indagações epistemológicas e lógicas, típicas em Husserl. No entanto, como não reconhecer que este último descobrira, no próprio movimento intencional ou na série das modalizações, o fenômeno originário da negação como um outramente, uma consciência de alteridade? Segundo Levinas, uma vivência pode ser tomada como modalidade porque se encontra numa situação de independência em relação à inteligibilidade que ela mesma ajudou a constituir, ou ainda, porque se situa para além do ser que comanda as modalidades da consciência. $\mathrm{O}$ exemplo privilegiado é o sofrimento. Este é a maneira pela qual a síntese é recusada. A dor humana desordena a ordem e, ao mesmo tempo, é o próprio desordenamento. Daí poder-se dizer que o sofrimento é consciência ao avesso, é "negação e recusa de sentido, impondo-se como qualidade sensível” (LEVINAS, 1997, p. 128). O vivido, enquanto dado de sensação, surge como a maneira de não-se-suportar, como o não suportar o insuportável (LEVINAS, 1997, p. 128-129). Não se trata de uma contradição lógica, mas contradição que remete ao sensível, à dor ou à dolência da dor.

O que conta na não-liberdade ou no padecer do sofrimento é a concretude do não que surge como mal, mais negativo que todo não apofântico. Esta negatividade do mal é, provavelmente, fonte ou núcleo de toda negação apofântica (LEVINAS, 1997, p. 130).

Com Husserl, Levinas aprende que as modalidades psíquicas comportam implicações intencionais, mas podem ser irredutíveis. Neste caso, a passividade está em condições de significar "independentemente de sua oposição conceitual à atividade" (LEVINAS, 1997, p. 129), bem como para além da relação entre ser e nada. Mesmo que a intencionalidade seja tributária do dinamismo verbal do ser, há um tipo de consciência que termina sendo irredutível a este dinamismo. Esta "consciência" não é submissão ao ser, mas a maneira de sua interrupção ou ultrapassagem. Eis por que se pode dizer que Levinas vai muito mais longe que Husserl. A negatividade não diz respeito à percepção em suas expectativas frustradas. No sofrimento, a passividade é vulnerabilidade, e não a receptividade de um sujeito ativo, transcendental, viril. Trata-se de um não concreto e radicalizado: a dissolução de todo sentido. Ora, a consciência intencional é sempre posicional, isto é, "põe algo como sendo" isto ou aquilo. 
Como em Husserl, a passividade originária é não-intencional, é consciência não-objetivante. Mas para Husserl somente o sujeito ativo ou agente poderia dar um sentido positivo a esta passividade. Em Levinas, ao contrário, a passividade não é puramente negativa, pois, à sua maneira, isto é, outramente, ela põe uma recusa de toda a síntese, uma impossibilidade de assunção, uma negação do próprio ato de tornar inteligível esta passividade. Numa palavra, ela põe uma inquietação ética incontornável. O mesmo se descobre questionado pelo outro. Na passividade mesma surge um sentido positivo, um despertar, uma consciência vigilante, uma inquietude (LEVINAS, 2002, p. 46). A negação, entendida como o mal da dor, não é somente a articulação do absurdo, pois a dor remete ao sujeito em sua dimensão sensível, vulnerável, dadivosa. Enquanto encarnação (incarnation), o eu está exposto ao outro, numa espécie de expulsão de sua concha e de seu abrigo. Que é o sujeito encarnado?

O sujeito encarnado (incarné) não é um conceito biológico. O esquema que delineia a corporeidade submete o próprio biológico a uma estrutura mais alta: des-pojamento (dé-possession) não certamente entendido como nada, mas sim como negatividade impetrada na impossibilidade de se esconder, sem nenhum campo de iniciativa (LEVINAS, 1996, p. 173, grifo nosso).

Negatividade propiciada pela encarnação. Esta é a possibilidade do oferecer-se ao outro. O sofrimento significa a partir do sofrimento do outro, daquele que me solicita, gritando por socorro. O sem-sentido se transforma em significação (saída de si em direção ao outro), despertar do eu vigilante, afetado pelo sofrimento alheio. Pode-se, ainda, recorrer à fenomenologia para se descrever esta vigília, este despertar, esta afetação?

\section{O eu vigilante: a negação como significação}

Segundo Levinas, Husserl mostrara a importância do sono e da vigília na vida do eu (LEVINAS, 2002, p. 43). Há, para essa vida, a estranha possibilidade de perceber-se invadida ou desestabilizada em sua intimidade, em sua interioridade. Em Experiência e juízo, a análise husserliana das modalizações não se volta, como em Idéias I, para atos dóxicos do Eu (HUSSERL, 2006, $\S 104$ ), isto é, para as diferentes tomadas de posição da consciência. É o pensar antepredicativo, compreendido como sendo receptividade, que se encontra em questão. Segundo Husserl, a consciência passiva não só é constituinte de objetos 
(HUSSERL, 1970, p. 71), como também exerce um papel de fundação para as diversas atividades do Eu. As formas predicativas do juízo surgem a partir da experiência antepredicativa, isto é, da experiência simples e imediata. Considerado a partir da esfera receptiva ou sensível, o Eu é sempre afetado, estimulado e provocado por tudo o que pertence a seu campo de percepção. Ele pode ceder ou não a esses estímulos, mas o objeto intencional sempre pode atraí-lo e afetá-lo.

Na medida em que é atraído, afetado, embaraçado, etc. ou Eu é um ser-em-vigília (Wachsein). Esta vigilância é uma potencialidade, um poder realizar atos (HUSSERL, 1970, p. 92). O ser em vigília consiste em dirigir o olhar para algo, mas este ato é, curiosamente, um sofrer efetivamente uma afecção. Em sua orientação para algo, o Eu está em condições de acolher aquilo que lhe é dado de antemão, vale dizer, aquilo que o afetou e sensibilizou. Trata-se da receptividade do Eu (Rezeptivität des Ich), ou seja, "o Eu consente àquilo que lhe advém, acolhendo-o em si” (HUSSERL, 1970, p. 93). Mas, na perspectiva husserliana, a passividade é apenas um grau inferior de atividade, ou, para dizer com Levinas (2002, p. 45), "o despertar responde ainda a uma alteridade a ser assimilada pelo Eu". Mesmo assim, em Husserl a vida do Eu não se absorve nunca no conhecimento conquistado. "A possibilidade do despertar já faz bater o coração do Eu” (LEVINAS, 2002, p. 46).

A afetação do Eu pelo "objeto" ou pelas situações em que se encontra tende a fazer-se ontologia, caminha para a solução totalizadora do saber, bem como para a sincronia do ser. Mas, enquanto modalidade psíquica irredutível, enquanto modalidade do desconcerto do mesmo pelo outro, a vigília é sempre mais do que o saber, pois é despertar em relação ao próprio saber, é um abrir-se à dimensão crítica do pensar. Portanto, a referência a um psiquismo irredutível torna-se decisiva para se compreender a modalidade do outramente. O Eu vigilante é uma diferença em relação a si, uma exceção em relação ao ser. Esta diacronia descreve-se como síntese absolutamente passiva do envelhecimento, lapso de tempo irrecuperável (LEVINAS, 1996, p. 66). A subjetividade humana mostra, portanto, a ambiguidade fundamental do ser e do outro que o ser. ${ }^{3}$ Por isso, a questão primeira não é saber em que sentido o outro questiona o mesmo, mas sim

"A diacronia significa apenas negativamente? Ela é pura perda? Ela não comporta significação?” (LEVINAS, 1996, p. 66). A pergunta é pela significação do terceiro excluído em relação ao ser e ao não-ser. Assim: "Por trás do ser e de sua exibição, ouve-se, desde então, a ressonância de outras significações esquecidas na ontologia, significações essas que clamam pela investigação" (LEVINAS, 1996, p. 67). 
como e onde se produz, no psiquismo da experiência, a ruptura maior, capaz de dar crédito a um outro como irredutivelmente outro e, nesse sentido, como além, uma vez que, na teia do pensável tematizado, todo dilaceramento conserva ou retoma a trama do Mesmo? (LEVINAS, 2002, p. 169, grifos do autor).

Como se vê, a pergunta é relativa à produção, no psiquismo, isto é, na esfera das vivências, de uma ruptura ou modalidade sem a qual o outro enquanto tal não seria digno de crédito. Ou, para dizer com Jacques Rolland, trata-se de apreender o outro "a partir da modalidade que lhe é própria", isto é, "em seu "como"” ou "em sua maneira" (ROLLAND, 2000, p. 3-4). Para que o outro enquanto tal signifique, requer-se o pensamento sob a forma de advérbio (advérbio de modo): outramente. É assim que, segundo Jacques Rolland, o pensamento se descobre como resistência ao risco de substancialização a partir de uma lógica do advérbio enquanto tal (ROLLAND, 2000, p. 5). O verbo ser, diacronia sincronizável, essência que se faz nome (LEVINAS, 1996, p. 72-73), não pode reconhecer as vivências que já não sejam recolhidas, nomeadas, representadas. Tomadas em si mesmas, as modificações temporais são apenas um debulhar da essência (LEVINAS, 1996, 73). Elas não têm significação própria. Assim, perguntamos: há uma lógica capaz de mostrar que os substantivos entram no discurso a partir do advérbio? Qual?

Certo, toda exibição ou mostrar-se do ser implica a temporalização, entendida como lapso de tempo recuperável. Mas o tempo, já ensinara o próprio Husserl, pressupõe um diferir em relação a si mesmo. É verdade que a consciência perceptiva pressupõe uma unidade sem ruptura, mas há, nesta unidade, certas diferenças. Cada instante é diferente do outro, embora não dissociado do outro. Em suas variações, a consciência temporal se recolhe na unidade (HUSSERL, 1996, p. 112). Mas temos aqui um problema. Que significa dizer, como faz Husserl, que há um diferir em relação a si mesmo, implícito na consciência do tempo? A esse respeito, Levinas é contundente: a exibição do ser enquanto fenômeno não pode prescindir da partição da totalidade do ser. Não há sincronia sem diacronia. Por isso, o mostrar-se do ser só é possível a partir do outramente, isto é, das fraturas, interrupções ou modalidades sem as quais a temporalidade sincrônica não poderia seguir o seu curso. Interpretando criticamente as análises husserlianas da consciência temporal, Levinas afirma: "a essência do tempo é temporalização do tempo - diástase do idêntico e sua reconquista ou reminiscência" (LEVINAS, 1996, p. 53). Mas esta reconquista realizada pela intencionalidade, e confirmada pela verdade do ser, depende do psiquismo irredutível, isto é, do psiquismo enquanto defasagem temporal ou 
ruptura da identidade. A esta modalidade psíquica Levinas chama significação do outro-no-mesmo.

Significação possível unicamente como encarnação. A animação, o pneuma mesmo do psiquismo, a alteridade no idêntico de um corpo se expondo ao outro, fazendo-se "para-o-outro": eis a possibilidade do dom (donner) (LEVINAS, 1996, p. 111, grifo do autor).

A subjetividade é a condição de possibilidade da exibição e da interrupção da temporalidade da essência. Por um lado, o lapso de tempo irrecuperável (partição da totalidade trazida pelo psiquismo irredutível, contestação do primado da intencionalidade pelo sensível) faz que o tempo seja a expressão do pensamento essencial como evento do próprio ser (Heidegger). Sem a sincronia, tudo seria dispersão pura. Por outro lado, enquanto caracterizada pelo psiquismo irredutível, isto é, pelas modalidades psíquicas sem doxa, a subjetividade é também o lugar (ou não-lugar) em que o outro do ser se produz sob a forma de "deferência ao Infinito" (LEVINAS, 1993, p. 131).

\section{Considerações finais}

O tempo, afirma Levinas (1993, p. 132, grifo nosso), é a "modalidade psíquica em que o acontecimento ontológico se desfaz". Na nossa perspectiva, isso significa: o outro toma sentido a partir da negação ou negatividade. Esta afeta o eu, despertando-o. Mas a negação, enquanto vivência irredutível ou passividade extrema (vulnerabilidade), descreve-se, também, como nãosentido, ausência de ordem, dor inexplicável. Eis a ambiguidade do sentido e do não-sentido (LEVINAS, 1996, p. 255). "O mal da dor, o próprio dano, é o esfacelamento e como que a articulação a mais profunda do absurdo" (LEVINAS, 1997, p. 130). No entanto, digamo-lo uma vez mais, enquanto modalidade psíquica irredutível, a negação questiona, desfaz (nega) interminavelmente o destino da essência. Entendido a partir deste não, o um-para-ooutro marca a origem de toda significação.

\section{Referências}

FRANCK, D. L'un-pour-l'autre. Levinas et la signification. Paris: PUF, 2008. 
HEGEL, G. W. F. Précis de l'encyclopédie des sciences philosophiques. Tradução de Jean Gibelin. Paris: Vrin, 1987.

HEIDEGGER, M. Qu'est-ce que la métaphysique? (Questions I et II). Paris: Gallimard, 1968.

HUSSERL, E. Expérience et jugement. Tradução de Denise Souche-Dagues. Paris: PUF, 1970.

HUSSERL, E. Leçons pour une phénoménologie de la conscience intime du temps. Tradução de Henri Dussort. Paris: PUF, 1996.

HUSSERL, E. Idéias para uma fenomenologia pura e para uma filosofia fenomenológica. Tradução de Márcio Suzuki. Aparecida, SP: Artes e Letras, 2006.

LEVINAS, E. Dieu, la mort er le temps. Paris: Grasset, 1993.

LEVINAS, E. En découvrant l'existence avec Husserl et Heidegger. Paris: Vrin, 1994.

LEVINAS, E. Altérité et transcendance. Montpellier: Fata Morgana, 1995.

LEVINAS, E. Autrement qu'être ou au-delà de l'essence. Paris: Le Livre de Poche, 1996.

LEVINAS, E. Entre nós: ensaios sobre a alteridade. Tradução de Pergentino Stefano Pivatto. Petrópolis: Vozes, 1997.

LEVINAS, E. De Deus que vem à idéia. Tradução de Pergentino Stefano Pivatto. Petrópolis: Vozes, 2002.

ROLLAND, J. Parcours de l'autrement. Paris: PUF, 2000.

Recebido: $18 / 07 / 2010$

Received: $07 / 18 / 2010$

Aprovado: $15 / 08 / 2010$

Approved: 08/15/2010 